\title{
O fotojornalismo entre profissionais e amadores: algumas leituras
}

\section{Photojournalism among professionals and amateurs: a few readings}

1 Luiz Antonio Feliciano luizliu@yahoo.com.br

2 Aline da Fonseca Pinna

1 Docente do Centro Universitário de Volta Redonda; Faculdades Integradas Teresa D'Ávila.

2 Discente do $8^{\circ}$ período do curso de Jornalismo, UniFOA.

\section{Resumo}

Este artigo trata das contribuições do fotojornalismo para a sociedade, desde o aparecimento das câmeras fotográficas até os dias atuais. Fala também do surgimento das câmeras digitais, a partir dos avanços tecnológicos e de sua importância na integração da fotografia na vida cotidiana, com a possibilidade de capturar imagens instantaneamente, dando liberdade aos usuários de alterarem a realidade fotografada. Por fim, o artigo relata a postura do fotojornalista diante das modificações das câmeras obtidas pela modernidade tecnológica.

\section{Palavras-chave}

Fotojornalismo; subjetividades; câmeras digitais; novas tecnologias; cotidiano.

\begin{abstract}
This article deals with the way photojournalism has contributed to society, from the appearance of photographic cameras to our days. It also deals with the appearance of digital cameras and technological advances, and their importance to integrate photography in everyday life, with the possibility of capturing images instantaneously, giving freedom to the users to change the photographed reality. Finally, the article deals with the photojournalist's attitude in face of the modifications of cameras caused by technological modernity.
\end{abstract}

\section{Keywords}

Photojournalism; subjectivities, digital cameras, new technologies, everyday life.

\section{Como você deve citar?}

FELICIANO, Luiz Antonio; PINNA, Aline da Fonseca. O fotojornalismo entre profissionais e amadores: algumas leituras. Cadernos UniFOA, Volta Redonda, n. 30, p. 57-67, abr. 2016. 


\section{INTRODUÇÃO}

Com a importância de passar informações para o público, a fotografia sempre foi usada como meio de retratar as notícias de um determinado momento. A partir dessa constatação, deu-se o início do fotojornalismo. Desde então, a fotografia tem assumido um papel essencial em todas as áreas, já que demonstra a realidade e traz uma evolução de liberdade de expressão. Constantemente, a imagem vem sendo naturalizada, confundindo-se com a própria realidade vivida.

Com o avanço da tecnologia, sobretudo a digital, o acesso à diversidade de dispositivos produtores de imagens tem possibilitado uma vivência pautada pela imagem. As imagens fotografadas no dia a dia têm possibilitado uma integração com a vida. Veem-se imagens a todo o instante, mas estas também são produzidas na mesma proporção. Com os diversos recursos disponíveis, atualmente, graças ao desenvolvimento tecnológico, há programas que oferecem a possibilidade de alterar os dados obtidos nas fotos. Essa prática, muito comum aos profissionais de laboratório, passou a fazer parte da vida das pessoas.

Com a fotografia digital inserida no fotojornalismo, percebe-se a influência da tecnologia sobre as relações sociais. Mesmo que as fotografias nos proporcionem um olhar diante da realidade, elas podem causar um estranhamento, quando se aplica a manipulação de objetos, cores ou, até mesmo, cenários.

A internet, muito presente no cotidiano, possibilitou o aparecimento de jornais e revistas on-line. Assim, a empresa fica mais próxima do público e a notícia chega mais rápido do que outros meios de informação. Isso fez surgir o webjornalismo, com o objetivo de ser um recurso narrativo jornalístico.

Este trabalho teve por finalidade analisar fotografias que estamparam as capas do Jornal $O$ Globo, durante o mês de maio de 2014, para verificar se os olhares dos fotógrafos amadores são influenciados pelos fotojornalistas e, em contrapartida, são, igualmente, influenciados pelos amadores. A análise realizada está longe de esgotar a temática proposta. Porém, acredita-se que problematizações consistentes são apresentadas para propiciar outras discussões em outros tempos e outros lugares. Contudo, é importante salientar que o jornalismo está presente no cotidiano e busca, nesse mesmo cotidiano, o seu alimento diário, bem como todas as suas mudanças.

\section{UM BREVE PERCURSO HISTÓRICO PELO FOTOJORNALISMO}

Com o surgimento da necessidade de informação, houve a relevância de mostrar, através de imagens, o que acontecia em diversos momentos. Uma maneira de informar a sociedade sobre os fatos ocorridos se deu através do fotojornalismo. 0 aparecimento do fotojornalismo, no Brasil, ocorreu ao final dos anos 40, com Jean Manzon, na revista $O$ Cruzeiro, na qual o fotojornalismo era considerado um meio de linguagem. Logo foi foi incorporado em outras revistas, como a Manchete. 0 fotojornalismo dessa época era realizado com câmeras não digitais.

A possibilidade da produção de câmeras digitais surgiu a partir da década de 70, mas essas câmeras não tiveram destaque porque eram de alto custo e tinham baixa capacidade de armazenagem. Seu desenvolvimento só se deu a partir de 1983, embora, nesse período, as câmeras só tenham servido como curiosidade tecnológica. Foi na década de 90 que ocorreu uma grande revolução, pois o desenvolvimento tecnológico gerou transformações no campo da comunicação, da estética e da informação. A partir do ano 2000, os avanços na área da informática expandiram o computador e o celular. Ambos passaram a ser capazes de armazenar e distribuir imagens e vídeos. Além disso, o surgimento da internet, como meio de transmissão de imagens, imprimiu mais velocidade nas transmissões. Isso exigiu câmeras mais potentes, principalmente no fotojornalismo, para acompanhar, com mais precisão, a rapidez da notícia. 
A fotografia passou a impressionar a população com suas construções imagéticas nos diversos campos da sociedade: cultural, econômico, político e social. Essas imagens registravam os diversos sentidos de interpretação do fotógrafo, sempre com a intenção de mostrar a realidade para contribuir com a participação das pessoas no cotidiano da informação. Além disso, elas ganharam a tarefa de serem propulsoras de imaginação e de julgamento.

Para alguns fotógrafos, a imagem digital consegue se separar da fotografia tradicional, pois, com os enormes avanços, ela trabalha com maior liberdade de expressão. É o mesmo caso do vídeo que, quando foi inventado, muitos achavam que iria tomar o lugar do cinema. Isso, de fato, não ocorreu, pois o videografismo adquiriu uma linguagem autônoma, com suas especificidades, que o tornou independente do cinema.

Com a predominância da estética publicitária ou cinematográfica a partir da década de 90 , o fotojornalismo sofreu um declínio mundial, deixando de lado o modo jornalístico e tornando-se algo mais ideológico. Prevaleceram, nesse momento, as imagens com tom de horror, com luzes e sombras explícitas.

Outro ponto a ser considerado é a velocidade na transmissão das imagens. A chegada do digital, considerando sua rapidez de informar, dificultou o impacto e a novidade. A circulação mais veloz das notícias, através da internet, fez com que as imagens se espalhassem, ao mesmo momento, por vários sites, redes sociais, blogs. Com isso, o que deveria ter um caráter de ineditismo, passou a ser visto como algo obsoleto.

\section{FOTOJORNALISMO E ALGUMAS PROBLEMATIZAÇÕES CONTEMPORÂNEAS}

Com um público ávido pela participação na informação, foi grande e significativa a importância dada à valorização de ver o fato acontecido. Isso reforça e justifica a importância da entrada da fotografia no jornalismo. A imagem fotográfica é um registro visual produzido e armazenado no mesmo instante em que o fato acontece, não dispondo de outro momento igual para a produção da imagem. A fotografia é sempre uma morte anunciada. 0 cenário, a época e os costumes ficam petrificados na fração de segundo em que a cena é fotografada. Essa constatação induz a procura e a valorização da profissão de fotógrafo de imprensa.

O fotojornalista é quem possui a verdadeira técnica fotográfica. É o profissional preparado para produzir imagens com a máxima qualidade estética e informacional. Porém, com a forte influência tecnológica e a necessidade de mostrar com rapidez as notícias e as imagens "quentes" (jornalismo factual), o fato também é transmitido por fotógrafos iniciantes e amadores. Nesse contexto, um fotojornalista que tem o papel de levar a informação da notícia via imagens fotográficas (escreve a notícia através das fotografias), se depara com o fotógrafo amador que centra sua preocupação somente nas questões estéticas da imagem, deixando de lado o conteúdo da informação. Mais ainda, uma nova estética que a condição digital contemporânea tem propiciado.

Como resultado dos avanços da tecnologia, surgiu, no meio jornalístico, uma crescente utilização dos recursos de montagem. Antigamente, existia essa prática, mas não com tanta influência como na atualidade. 0 photoshop acendeu as luzes do laboratório fotográfico. Trocou-se a magia da luz vermelha, estereótipo de fotografia convencional, pela frieza das luzes fluorescentes, aclamada pela sua claridade. Com a manipulação das imagens, surgiu também o problema da ética, comum ao universo da comunicação. Nesse sentido, o que a fotografia tem ocultado da realidade? Com o objetivo de tornar a imagem mais atraente aos leitores, abre-se mão do conteúdo em favor da forma, que tem se tornado uma das preocupações dos profissionais de imprensa e de todos que utilizam a fotografia como 
material de trabalho ou pesquisa: o excesso de manipulação da imagem pelas agências de notícias, pois as imagens digitais podem ser facilmente arranjadas, rearranjadas e deletadas, diferentemente dos negativos convencionais.

Quando dizemos que a fotografia não mente, podemos estar equivocados. A fotografia sempre foi vista como um passar a realidade para as pessoas e, até hoje, ela, ainda, mantém as mesmas características. É a força da analogia que o signo fotográfico carrega. Para Barthes (1980), seu caráter análogo, sua semelhança com o referente, caracteriza um dos noemas da fotografia: o "isso foi". No entanto, a possibilidade de modificar a expressão das pessoas fotografadas, rejuvenescendo-as ou envelhecendo-as, põe em xeque essas convicções. Pode-se transformar um dia ensolarado em uma noite nebulosa ou, para ser mais ousado, pode-se suprimir ou acrescentar elementos e personagens na imagem. Isso reforça o que diz Fontcuberta (1997, p. 15): "Toda fotografíaes una ficción que se presenta como, verdadeira".

A facilidade de acesso às imagens interfere na sua visibilidade, trazendo o poder da edição. Cortes, brilho, contraste, saturação de cores, alteração da resolução, tamanho, retoques, deformações, enquadramento, correção de foco, entre outros, se tornam comuns no processo de edição. Dessa forma, com as enormes variantes de mudanças, acaba-se por alterar a forma original da fotografia. Essas montagens são produzidas em softwares de edição, como, por exemplos, o Photoshop, Digital Darkroom, Photostyler e outros. Uma fotografia contendo algumas dessas mudanças faz com que os leitores sejam desrespeitados e, além disso, interfere, extremamente, na credibilidade do fotógrafo e da memória fotográfica. Essas características são tidas como uma distinção entre a fotografia analógica e a digital, presente atualmente. Para Batista (2002, p. 36),

esta é a principal diferença da fotografia, digamos, convencional para a fotografia digital. A natureza da imagem formada por pixels permite que ela seja duplicada sem qualquer alteração ou perda de qualidade, assim como ser modificada em cada um dos seus milhões de pixels. Os programas são capazes de fazer alterações sutis, pixel por pixel, e também mudanças gerais rápidas.

O fotógrafo americano Lewis Hime (apud OLIVEIRA, 2010, p. 02) afirma que "embora as fotografias não possam mentir, os mentirosos podem fotografar". Essa colocação demonstra que há mentirosos por trás das câmeras. Porém, temos que lembrar que nem todos manipulam e editam suas fotografias e que há, sim, verdadeiros profissionais querendo retratar a realidade sem prejudicar a linha editorial dos veículos de comunicação.

A utilização da manipulação nas fotografias, muitas vezes, é quase impossível de ser vista. Retoques, modificações, redução ou aumento de contraste, reenquadramento, semi-máscaras, ocultação ou inclusão de elementos nas imagens são práticas que se tornaram comuns no cotidiano das pessoas e das empresas. Outro ponto a ser discutido é que o tratamento da imagem pode permitir, ainda, a combinação de uma fotografia com outra ou, até mesmo, com várias. Esse processo incorpora diversas novas tarefas, além de incluir as de modificação dos elementos construtivos da imagem, deixando de ser somente a escolha da foto, o recorte do quadro e sua inserção numa publicação. No Brasil, são frequentes as descobertas de casos de manipulação de imagem e a maioria dessas alterações foi feita em jornais (OLIVEIRA, 2010: p. 07).

A edição de uma fotografia pode ser feita pelo fotógrafo ou, então, pelo editor de fotografia, que vai selecionar certas imagens para compor as páginas do veículo de comunicação. Após esse processo, muitas fotografias são apagadas por falta de espaço, uma prática evitada pelo próprio fotógrafo. Os arquivos que não são armazenados podem ser prejudiciais, pois causam um sério risco de perda de dados de um determinado acontecimento, além, ainda, de apagar imagens que podem ser mais importantes que outras. Nessa perspectiva, o arquivamento das imagens tem se tornado um grande 
problema. Com as perdas de algumas imagens, poderá haver dificuldade, pois elas podem ser muito importantes em outro momento. As fotografias que podem, hoje, não ter valor, podem ter uma enorme relevância no futuro. Segundo Batista (2002, p. 43),

\begin{abstract}
o problema do arquivamento é complexo. No processo convencional o fotógrafo chega à redação com o filme, o filme é revelado, uma ou algumas fotos são escolhidas e o filme inteiro é arquivado. Já com a câmera digital, o fotógrafo chega com o material magnético cheio de sinais produzidos por descargas elétricas - que poderão virar fotos - descarrega as que ele considera melhores, editando apenas algumas e removendo as demais (que são deletadas, na linguagem da informática). Essa edição feita imediatamente após a produção das imagens deve-se ao problema que as editoras estão encontrando para o arquivamento de imagens digitais. Esses arquivos que formam as imagens são muito grandes e se todas as imagens obtidas forem guardadas, uma enorme quantidade de megabytes precisarão ser salvos em diferentes mídias, gerando um trabalho grande para os departamentos de pesquisa e arquivamento.
\end{abstract}

Outo problema enfrentado é a busca de mais rapidez na visualidade de uma imagem. Isso surge, paradoxalmente, como uma solução e uma vantagem para a imprensa. Com o aparecimento da internet no meio da comunicação, houve a necessidade de agilidade nas transmissões para o público e, assim, um maior interesse a todos. Quase todos os jornais e revistas possuem suas versões on-line, em que as notícias são atualizadas a cada nova informação e, dessa maneira, esse tipo de mídia é abastecido com matérias, 24 horas por dia. Isso mostra que não existe o famoso "fechamento" de um jornal ou edição, pois o surgimento de diversas informações novas, a qualquer momento, obrigam os sites a serem, sempre, o mais rápido possível. O fechamento se dá após o momento em que chega uma novidade, seja ela uma informação ou uma fotografia. A velocidade e a instantaneidade da informação têm reforçado outro aspecto muito presente na vida dos fotógrafos: o ineditismo. É grande, mesmo com a correria do dia a dia, a busca por imagens que nenhum outro profissional tenha. Nessa ânsia por fotografias inéditas, os profissionais de imprensa se esquecem, muitas vezes, de passar a informação para as pessoas. Dá-se mais valor à forma do que ao conteúdo. De certa maneira, inverte-se a ótica de importâncias. Aquilo em que o jornalismo sempre se pautou, a informação, cede lugar a espetacularização que a imagem pode principiar.

\title{
4 WEBJORNALISMO NA CONVERGÊNCIA TECNOLÓGICA DA NOTÍCIA
}

Como mencionado anteriormente, junto a todas as transformações que a tecnologia digital possibilitou aos meios de comunicação, apareceu, também, a web. Nela foi empregada a fotografia como forma de um recurso narrativo jornalístico. Inicialmente, não se pode afirmar que há grandes diferenças entre a imagem fotográfica exposta na webe a utilizada no jornalismo impresso (FELZ, 2008). Porém, se de fato a imagem jornalística aparecer juntamente com uma legenda ou um pequeno texto escrito, então, é lei, no fotojornalismo, que a fotografia produzida seja legível e clara. Uma diferença pode ser o suporte técnico das fotografias, já que no jornalismo on-line, as imagens se aproximam daquelas da televisão e no jornalismo impresso, o leitor tem as imagens no papel, ou seja, em suas mãos. Na web, o público pode perder um pouco da emoção que se deseja transmitir. Porém, a imagem não vai perder a sua função legitimadora.

As empresas jornalísticas repararam que o poder da internet era imprescindível. Dessa maneira, elas se tornaram o primeiro setor industrial a apadrinhar tal acontecimento. Em cerca de cinco anos, podia-se notar que todos os jornais tinham a presença da web, pois ela permitiu um novo modo de se fazer jornalismo. Com o seu surgimento, a web mostrou que era necessário que os jornalistas fizessem uma especialização para trabalhar com esse novo meio. Segundo Batista (2002, p. 40), 
diante dessa predominância da eletrônica e da informática nas práticas das redações pode-se perceber uma nova valorização das equipes de arte em geral. A própria denominação das funções mudou e o antigo diagramador virou designer ou diretor de arte. E o papel profissional exercido se modificou e, devido às novas habilidades requeridas para o manuseio do aparato tecnológico exigiu mudanças na sua preparação e formação, que agora deve capacitá-lo para o uso de softwares sofisticados de tratamento de imagens e diagramação de páginas.

Quando são colocadas as matérias para o meio de comunicação, o que é mais privilegiado é o texto. Ele deve ser leve e de fácil entendimento para a web. No momento em que é transportada a matéria do impresso para o on-line, as imagens jornalísticas são tidas como segundo plano. Os jornais não estão mais tão satisfeitos com somente o material impresso. Dessa forma, as empresas jornalísticas estão, cada vez mais, aderindo ao conteúdo para a rede, mesmo que de forma precária e limitada. Em reportagens mais relevantes, a fotografia é utilizada com a função de ilustrar a notícia.

Vale registrar também que nem todo público da web possui uma conexão de alta qualidade e velocidade e/ou máquinas de última linha. Assim, o oferecimento de imagens com resoluções baixas é a maneira mais viável para possibilitar a sua visualização, dado a limitação dos equipamentos tecnológicos, da maioria dos usuários. Pensando nesse grande público, os jornais on-line preferem fornecer imagens de baixa qualidade (porém organizadas), para que as pessoas possam visualizar esse material de forma mais rápida e completa. Atualmente, alguns jornais de terceira geração já possuem máquinas mais modernas que oferecem uma estrutura mais veloz e de ótima qualidade. Isso, associado aos melhoramentos que a internet tem recebido, tem propiciado maior facilidade no recebimento dos conteúdos jornalísticos on-line, sejam eles textos ou imagens. Para um webjornal obter um bom prestígio, a fotografia aparece em destaque, com tamanho maior, na primeira página. Outra forma usada é a sequência de imagens para relatar os fatos, o encaixe de sons e de comentários dos internautas e da empresa jornalística. Isso contribui para manter um bom relacionamento entre ambas as partes.

O crescimento do fotojornalismo tem como fundamento uma enorme movimentação da estética e da tecnologia. 0 aparecimento da web fez com que uma briga por espaço se tornasse frequente com novas formas de produzir e fornecer as notícias.

\section{PROFISSIONAL E AMADOR: OLHARES HÍBRIDOS}

As fotografias produzidas cotidianamente têm permitido uma integração maior com a vida contemporânea. Veem-se imagens a todo o instante, pois elas são tiradas a qualquer momento. Diversos são os propósitos para tal ação. Às vezes, para guardar determinada cena, outras para fixar alguma lembrança. Mesmo que fotografias nos proporcionem um olhar diante da realidade, elas podem causar um estranhamento, quando se aplica a manipulação de objetos, cores ou, até mesmo, cenários. Nos jornais impressos a fotografia é um meio de atrair o leitor. Isso pode ser uma estratégia para que o público "consuma" diariamente esse veículo.

Há jornais impressos que utilizam o recurso da manipulação, como, por exemplo, o clareamento da imagem, o escurecimento, entre outros recursos. A modificação da fotografia é muito usada nos meios de comunicação. Com a fotografia digital inserida no fotojornalismo, percebe-se a influência da tecnologia sobre as relações sociais.

Várias empresas de notícias têm se aproveitado da generosa produção fotográfica amadora para estampar imagens em seus sites de notícias. De certa maneira, o olhar amador sobre sua cotidianidade tem se tornado notícia e, mais ainda, notícia vendável. Esses "fotojornalistas amadores" estão tendo um espaço na mídia, pois também captam imagens "únicas", ou seja, também conseguem tirar fotografias que emocionam ou, mesmo, que "chocam" as pessoas. 
A Figura 1 mostra a situação da cidade de Duque de Caxias diante da empresa da Petrobrás. 0 jornal é de uma quinta-feira, 01 de maio de 2014. Não há muita informação a fundo, pois o destaque está voltado para a imagem, tanto que ela está em grandes proporções no espaço da capa. Esta fotografia de paisagem é um exemplo de fotos vistas diariamente, pois é característica, nos fotógrafos amadores, a busca por imagens que retratem paisagens naturais ou urbanas. A reprodução dessas características faz com que o jornal se aproxime mais do público, consequentemente, a fotografia se aproxima, igualmente, da visualidade amadora. A zona mais escura traz certa tridimensionalidade e certa profundidade à imagem. Traz, ainda, uma obscuridade, uma incapacidade enxergar, como metáfora da própria situação da Estatal.

Figura 1 - Nuvens negras

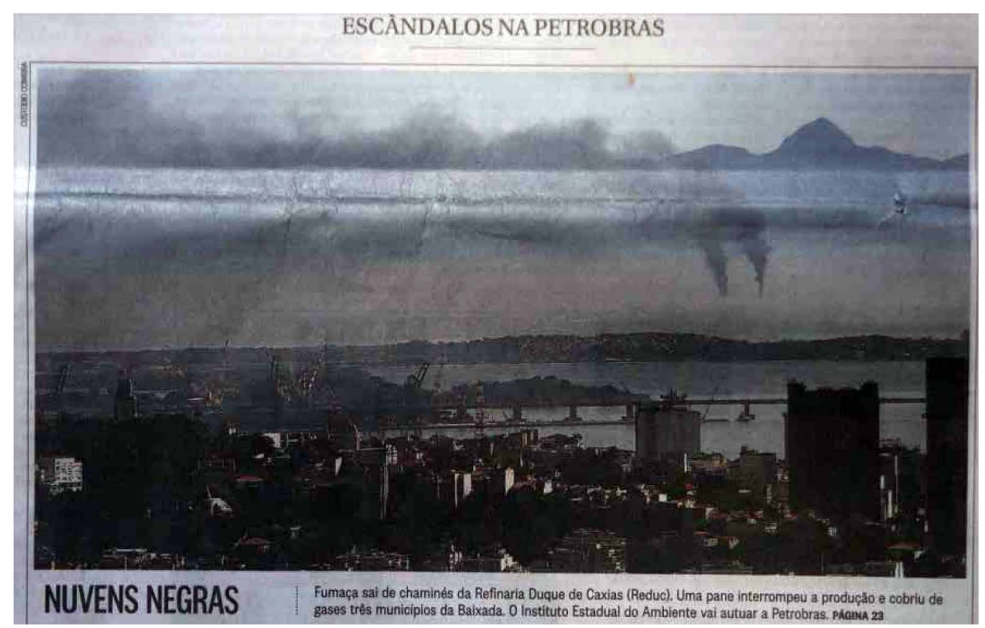

Fonte: Fotógrafo Custódio Coimbra - Jornal O Globo - 01 de maio de 2014

A Figura 2 é como a primeira foto analisada. Porém, não veio com título na parte superior, somente com um pequeno texto informando ao leitor do que se trata. A fotografia saiu na capa do $O$ Globo numa terça-feira, 06 de maio de 2014. Como a imagem tem um grande impacto, mais uma vez veio ocupando um espaço maior. Possui um ar distante com tons cinzentos e frios, dando certa profundidade e tridimensionalidade à imagem. Além disso, há uma sensação de movimento perante aos pedestres passando pela calçada ao fundo. $O$ leitor somente irá entender do que se trata a imagem, quando ler a legenda, entretanto, tendo como referência a data e os assuntos tratados já terão uma noção do que se trata. A cena é muito comum na capital do Rio de janeiro, pois mostra a convivência entre militares e civis no mesmo espaço: a cotidianidade e assunto que se desdobra nas produções visuais contemporâneas.

Figura 2 - Está chegando a hora

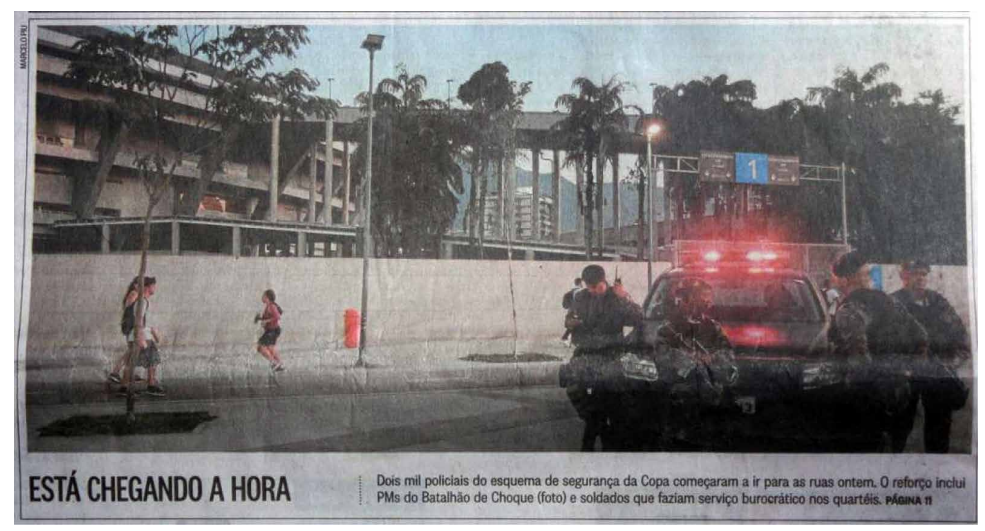

Fonte: Fotógrafo Marcelo Piu - Jornal O Globo - 06 de maio de 2014 
A publicação da Figura 3 foi feita na capa do jornal do dia 11 de maio de 2014 (domingo). A imagem é baseada em algumas composições fotográficas, como a luz e sombra. A utilização desses elementos causa um efeito proposital, possibilitando ver a imagem de outra maneira. 0 tamanho e a visibilidade da sombra é uma parte importante na imagem, de modo que crie uma composição simétrica.

Assim, podemos analisar que, ao enquadrar a imagem, a própria luz e sombra tornam-se o centro da atenção. A cena principal, os trabalhadores, se converte numa escuridão, causada pela silhueta. Um quase não querer mostrar ou, tão somente, um não pode (não deve) ser mostrado. Ou, ainda, a invisibilidade de certos setores da sociedade. Ao fundo, nota-se uma cidade edificada, focada e iluminada, sem vestígios de reformas ou de outras interferências.

\section{Figura 3 - Sem barreira}

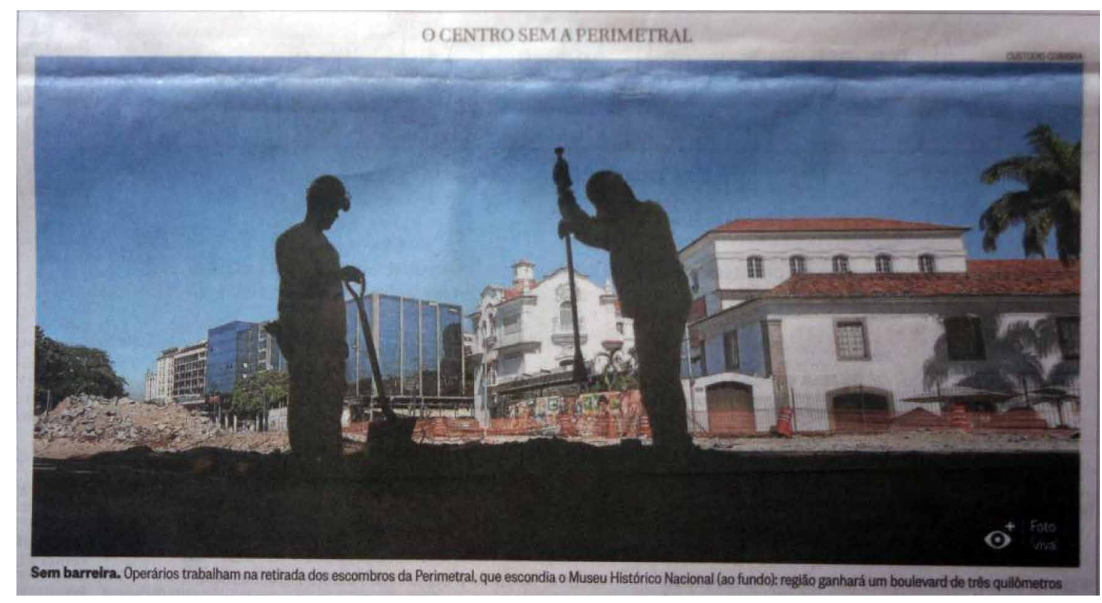

FONTE: Fotógrafo Custódio Coimbra - Jornal O Globo - 11 de maio de 2014

Esta fotografia (Figura 4) está na vertical, única nessa posição em relação às outras. A imagem foi publicada em 23 de maio de 2014 (sexta-feira). Ela transmite uma sensação de movimento por causa da circulação dos veículos na rua. A composição fotográfica e o enquadramento presentes apresentam uma integração entre todos os elementos encontrados. Um olhar comum sobre uma cena do cotidiano urbano, quase um protótipo dos olhares amadores.

A familiaridade com a cena ou a fidelidade com a pauta fotográfica castra o fotógrafo de qualquer possibilidade criativa. Muitas vezes, é mais cômodo oferecer algo simples, passível de uma identificação instantânea, do que causar um impacto reflexo-interativo no leitor. De certa maneira, a obviedade de grande parte do fotojornalismo, escorada na necessidade da informação, impossibilita inovações criativas na linguagem fotográfica. 
Figura 4 - No lado oposto

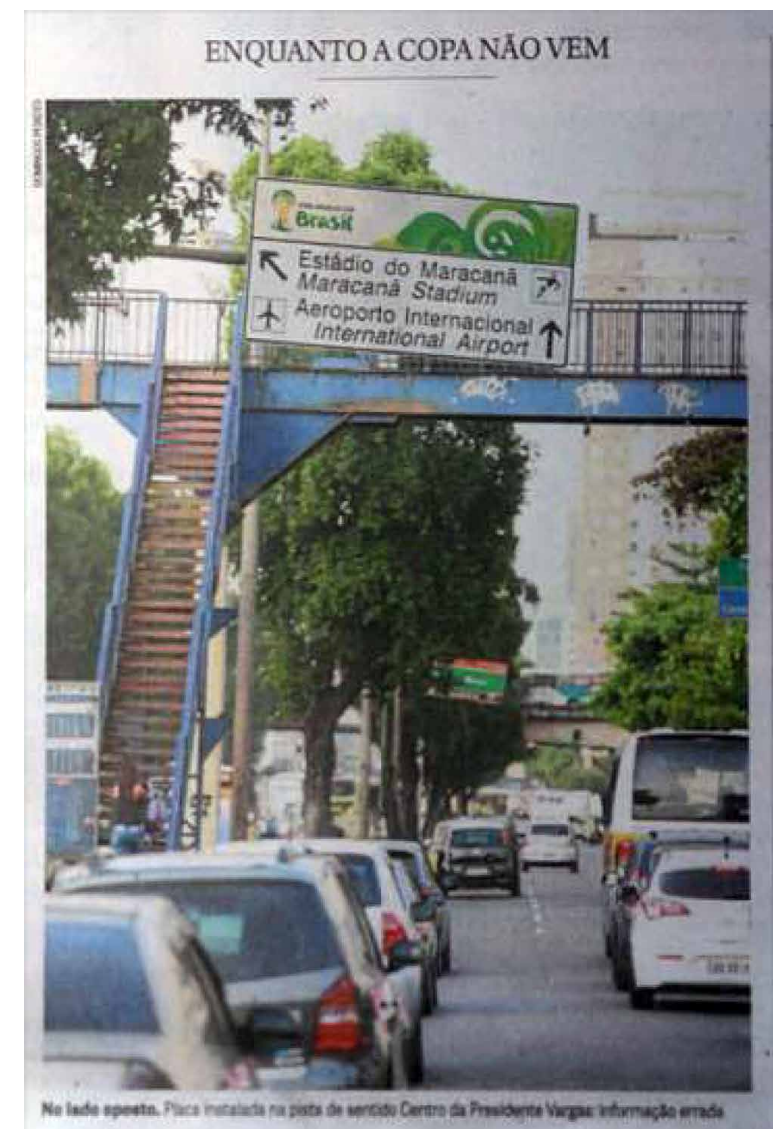

FONTE: Domingos Peixoto - Jornal O Globo - 23 de maio de 2014

A publicação da Figura 5 aconteceu em um domingo (25 de maio de 2014). A ligação da imagem com o título "Viciados em craque" traz um duplo sentido. Somente quando o leitor lê o pequeno texto, abaixo da fotografia, consegue entender o verdadeiro sentido que essa junção quer mostrar aos leitores. Verifica-se que, novamente, o fotógrafo utiliza a luz e a sombra como elemento de composição da imagem. Essa escolha favorece a duplicidade da mensagem sugerida pela junção entre o texto e a imagem. Os efeitos de conotação da imagem, discutidos por Roland Barthes (1961), se aplicam, ganhando característica de um fotojornalismo atuante e integrado, com linguagem informativa e discursiva.

Com essa sensação de duplo entendimento, as sombras trazem à tona o sentido de ocultar o ilícito. Na imagem, uma associação com a droga "crack", as figurinhas dos craques da Copa viram uma mania, quase semelhante a um vício. Esconder detalhes importantes na imagem facilita a utilização das conotações visuais, como proposto por Barthes (1961), pois faz com que o sentido conotativo se sobressaia ao sentido denotativo. Essa percepção se dá quando a fotografia trabalha os códigos pertencentes ao universo cultural do leitor. Por esse viés, a imagem 05 consegue duplicar os caminhos de leitura. 
Figura 5 - Viciados em craque

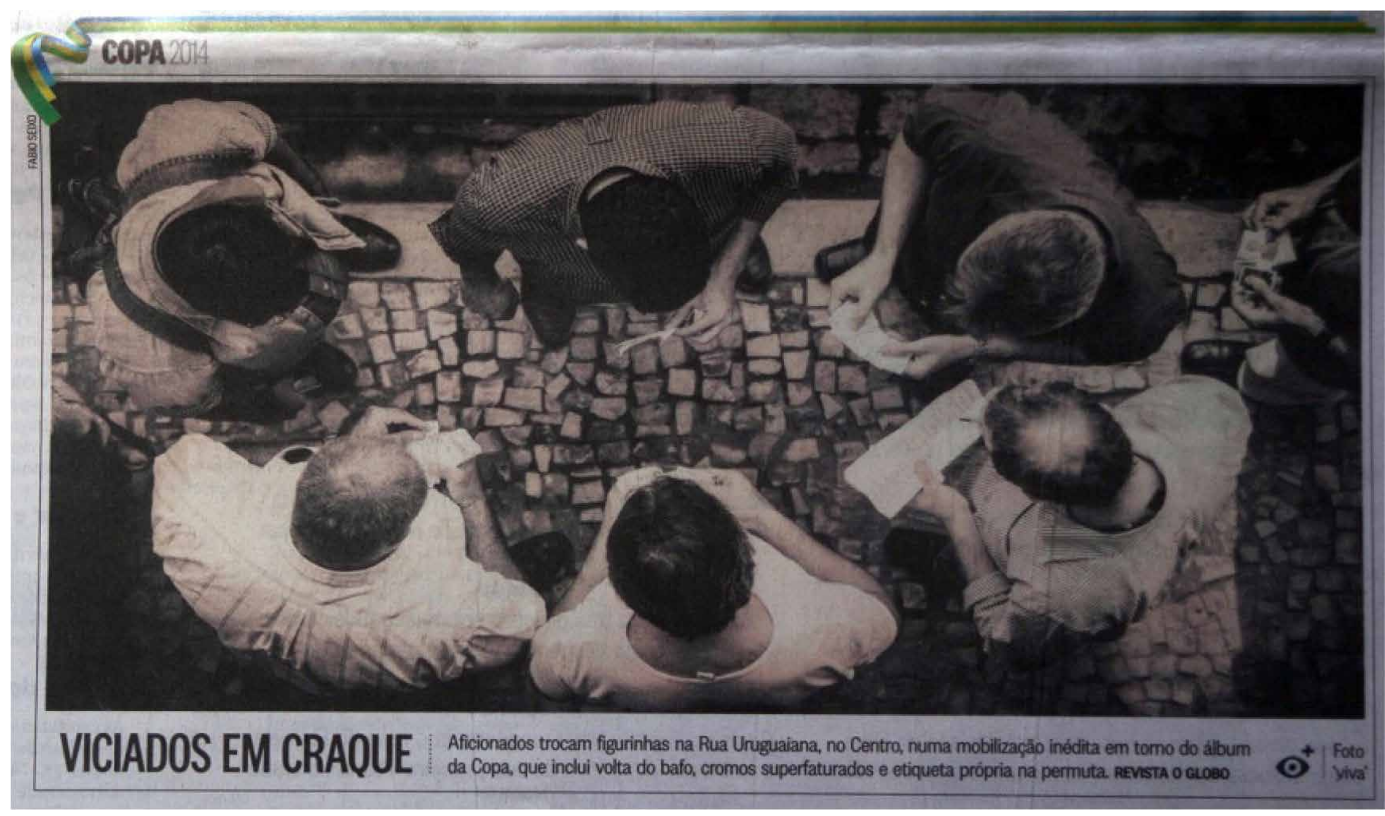

Fonte: Figura 5 - Fábio Seixo - Jornal O Globo - 25 de maio de 2014

Do ponto de vista amador, é uma fotografia que carrega vestígios da cotidianidade, por ter um ângulo alto extremo, muito característico de fotografias de moradores de apartamentos. É muito comum a produção de imagens das cenas cotidianas que acontecem nas ruas ao entorno dos edifícios. Diversas fotografias veiculadas na internet apresentam essas características. 0 fotógrafo amador se vale de suas leituras visuais para construir o olhar que ele lança sobre a realidade que quer registrar. As imagens analisadas trazem um pouco dessas interferências e desses condicionamentos. Não esgotamos todas as tentativas para subsidiar o trabalho, mas acreditamos que acendemos o estopim para outras discussões.

\section{CONCLUSÃO}

A tecnologia tem possibilitado uma maior produção fotográfica em todos os setores e camadas sociais. A internet, por sua vez, facilita a veiculação de conteúdos amadores e profissionais, sejam eles informativos, opinativos ou artísticos. Concomitante a esses avanços, o webjornalismo surge com o propósito de agilizar a veiculação de informações jornalísticas. Nesse contexto, a abertura para a inserção de fotografias amadoras, nesses espaços on-line, possibilita a criação de "fotojornalistas amadores". 0 olhar descompromissado sobre o cotidiano ganha novas abordagens. Com isso, os reflexos do fotojornalismo estarão presentes nas fotografias amadoras, que passam a olhar o cotidiano como "conteudistas" (caçadores de conteúdos).

Da mesma maneira, o fotojornalismo começa a ganhar um pouco da cara dos olhares amadores. Os enquadramentos e os ângulos tomados trazem à tona a interferência de ambos, profissional e amador, em suas produções. 0 olhar amador e o olhar profissional se constroem mutuamente. Com o avanço das tecnologias da produção e circulação da imagem, isso se intensifica. Os olhares se multiplicam e se esbarram pelas redes on-line, em um duplo movimento. Os profissionais têm acesso aos conteúdos amadores e os amadores se embebedam visualmente com as produções fotográficas dos fotógrafos profissionais. Um movimento constantemente reforçado pela própria dinâmica social contemporânea. 
Acreditamos, dessa maneira, na contribuição da fotografia amadora para a construção de uma nova "estética visual", nos parâmetros propostos por André Parente (2007). Uma estética construída a partir de outros referentes. Uma referência que brota das experiências vivenciadas na cotidianidade e que se amálgama com outros referenciais que pairam no universo on-line. As imagens do Jornal $O$ Globo escolhidas para a análise trazem um pouco dessa hibridização, que consistem na experiência estética da fotografia nos dias atuais. Isso aponta para a necessidade do profissional de jornalismo ficar cada vez mais atento para as mudanças que a vivência em sociedade configura. Não observar essas transformações é "perder o bonde da história". De toda maneira, as problematizações, por ora levantadas, reforçam a tese de que o fotojornalismo se encontra diariamente entre as pessoas, sendo elas profissionais ou amadores.

\section{REFERÊNCIAS}

BAPTISTA, Eugênio Sávio Lessa. Fotojornalismo digital no Brasil: a imagem na imprensa da era pósfotográfica. Dissertação de mestrado. Rio de Janeiro: UFRJ, 2002.

BARTHES, Roland. A Câmara clara. São Paulo: Ed. Nova Fronteira, 1984.

BARTHES, Roland. "A mensagem fotográfica". In: 0 obvio e o obtuso. Lisboa: Edições 70, 1984.

FELZ, Jorge Carlos. "Fotojornalismo na web: atuação de alguns conceitos e usos a partir da análise das imagens fotojornalísticas disponíveis no UOL Notícias". In: Associação Brasileira de Pesquisadores em Jornalismo. São Paulo: UMESP, nov. 2008.

FONTCUBERTA, Joan. El beso de Judas: fotografía y verdade. 4. ed. Barcelona: Editorial Gustavo Gili SA, 2002.

GIL, Antonio Carlos. Métodos e técnicas de pesquisa social.6. ed.. São Paulo: Atlas, 2008.

JORNAL O GLOBO. Edições de maio de 2014.

OLIVEIRA, Erivam Morais de. "O resgate da ética no fotojornalismo: a banalização das imagens nos meios de comunicação". In: Fórum Nacional de Professores de Jornalismo. Viçosa-MG: 2010.

PARENTE, André. "Cinema em trânsito: do dispositivo do cinema ao cinema do dispositivo". In: PENAFRIA, Manuela; MARTINS, Índia Mara (Org.). Estéticas do digital: Cinema e Tecnologia. Covilhã-PT: Livros LabCom, 2007.

PERSICHETTI, Simonetta. "A encruzilhada do fotojornalismo". In: Discursos fotográficos. Londrina: 2006, v.2., n.2, p.179-190.

SOUSA, Jorge Pedro. Uma história crítica do fotojornalismo ocidental. Porto: Universidade Fernando Pessoa, 1998, $320 \mathrm{p}$. 